\title{
In-sewer Treatment System of Enhancing Self-Purification: Performance and Oxygen Balance in Pilot Tests
}

\author{
Tadashi SHOJI ${ }^{1}$, Yoshiharu MATSUBARA ${ }^{2)}$, Satoshi TAMAKI ${ }^{2)}$, Katsuo MATSUZAKA ${ }^{2)}$, \\ Hiroyasu SATOH ${ }^{1)}$, Takashi MINO') \\ 1) Department of Socio-Cultural Environmental Studies, The University of Tokyo, 5-1-5 \\ Kashiwanoha, Kashiwa, Chiba 277-8563, Japan \\ 2) Research and Development Institute, Urban Infrastructure and Environmental Products \\ Company, Sekisui Chemical Co., Ltd., 2-2 Kamichoshicho, Kamitoba, Minami-ku, Kyoto \\ 601-8105, Japan
}

\begin{abstract}
A novel sewer pipe with a double-deck structure was developed for in-sewer treatment. The upper deck is designed for the smooth transportation of wastewater, while the treatment is conducted by sponge media in the lower deck, which is intermittently exposed to wastewater and oxygen as with a trickling filter. The performance of the novel pipe was examined in the pilot-scale demonstration fed with domestic wastewater for 9 months. The indices of organic matter (BOD, COD, and SS) decreased for several hours of batch-mode recirculating tests. The removal rates ranged between 12 and $39 \mathrm{~g}-\mathrm{COD} /(\mathrm{m} \cdot \mathrm{d})$ and were not significantly affected by temperature $\left(18-29^{\circ} \mathrm{C}\right)$ and flow rate $\left(6-15 \mathrm{~m}^{3} / \mathrm{h}\right)$. The estimated oxygen requirement was balanced with the intermittent oxygen supply, i.e., sum of reaeration with water flow and direct exposure without water flow. Furthermore, the performance of the novel pipe coupled with simple post-treatments was also examined. The coagulation was the most efficient: BOD was successfully decreased to below $20 \mathrm{mg} / \mathrm{L}$ by the in-sewer treatment for $3.5 \mathrm{~h}$ followed by the addition of $100 \mathrm{mg} / \mathrm{L}$ of polyaluminum chloride. The novel pipe, therefore, may be promising technology for both COD reduction (independent usage) and alternative secondary treatment (coupled with coagulation).
\end{abstract}

Keywords: domestic wastewater, in-sewer treatment, oxygen balance

\section{INTRODUCTION}

A sewer system can serve not only as a transportation network but also as a transformation reactor for municipal wastewater because there are significant amount of biomass in the form of suspended bacteria and sewer-wall biofilm. Since the pioneering work by Pomeroy and Parkhurst (1972), several studies have been conducted over the past few decades on the oxidation/degradation process, referred to as self-purification in a sewer. It has been recognized that shifts in both the quantity and quality of organic matter can occur during transportation of wastewater (Nielsen et al., 1992). With regard to the quantity, Huisman et al. (2004a) reported that no less than $30 \%$ of the dissolved chemical oxygen demand (COD) could be oxidized in a full-scale gravity sewer. As for the quality, both modeling (Gall et al., 1995) and experimental (Raunkjær et al., 1995) approaches showed the changes in the dissolved-COD/particulate-COD ratio and specific components such as volatile fatty acids, carbohydrates, lipids, and proteins. These results suggest that self-purification may strongly affect the design and operation of wastewater treatment plants (WWTPs), which are located at the ends of sewer systems (Nielsen et al., 1992). From a practical viewpoint, the oxidation of organic matter deserves careful attention because it has the potential to reduce the loading of

Address correspondence to Tadashi Shoji, Department of Materials and Life Science, Seikei University,

Email: t-shoji@st.seikei.ac.jp

Received June 15, 2015, Accepted September 13, 2015. 
organic matter to WWTPs. This reduction in load could result in space and cost savings, especially for densely populated cities (Green et al., 1985; Chen et al., 2001) and coastal or tourist areas (Baban and Talinli, 2009).

When regarding a sewer system as a bioreactor for the degradation of organic matter, referred to as in-sewer treatment, the performance is mainly governed by the quantity of biomass. Some researchers have proposed the addition of activated sludge as a possible option to keep enough biomass in sewer pipes (Koch and Zandi, 1973; Green et al., 1985). However, this concept inevitably requires the installation of a large amount of aeration equipment, which is presumably the main reason that it has not been put into practical use so far. On the other hand, Tanji et al. (2006) and Marjaka et al. (2003) conducted lab-scale experiments to evaluate the modification of the surface of sewer pipes to promote biofilm attachment. Moreover, Baban and Talinli (2009) prepared a lab-scale pipe equipped with Raschig rings as attaching media solely to evaluate its flow characteristics. Although these "modified pipe" approaches seem to be attractive options in order to enhance the in-sewer treatment, there is another problem to be solved: compatibility with transportation. The modified surface and/or the equipped media must not result in long-term obstruction of the transportation of wastewater, which can contain a lot of suspended solids. To the best of our knowledge, no "modified pipe" technology has been developed so far to achieve both smooth transportation and enhancement of in-sewer treatment.

In the present study, we propose a novel sewer pipe (referred to as a purifying pipe hereafter) that is characterized by a double-deck structure with a separator, as illustrated in Fig. 1a. Two decks are designed for different functions: the upper deck for smooth transportation and the lower deck for self-purification. When the flow is high, most wastewater falls to the lower deck through the holes located along both sides of the separator. Since the sponge media, i.e., the attached biomass in the lower deck, are mainly exposed to wastewater, this condition is suitable for the biomass to take up organic matter. When the flow is low, on the other hand, most wastewater is transported on the upper deck. Since the sponge media are mainly exposed to air, this condition is suitable for the biomass to utilize oxygen and degrade the taken-up organic matter. As for the compatibility with transportation, blockage by sewage solids can be avoided because they are too large (gross solids and garbage) or too heavy (sand) to fall through the holes, and thus they are mainly transported through the upper deck with the remaining wastewater. Blockage by the excess biomass can also be avoided because the smooth surface of the upper deck is not suitable for biomass growth. Moreover, it should be noted that the enhanced reaeration by the overflow (fall) of wastewater (Almeida et al., 1999) as well as the direct exposure can be an additional source of oxygen for the purifying pipe as with a trickling filter, in comparison with a conventional sewer pipe that is supplied by surface aeration only.

To confirm these theoretical advantages of the purifying pipe, we conducted a pilot-scale demonstration in which the pipe was fed with domestic wastewater for 9 months. The main purposes of this paper are to examine the performance under various operational conditions and to estimate the consistency of the oxygen balance. Some post-treatments were also investigated as a novel and inexpensive alternative corresponding to the conventional secondary treatment. 

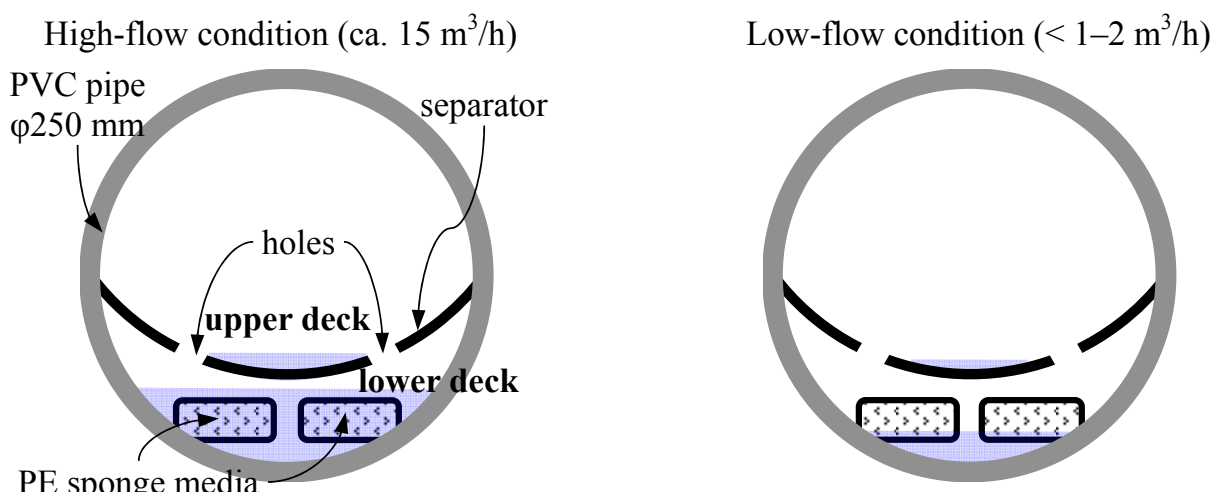

(a) Cross-section view of the purifying pipe.

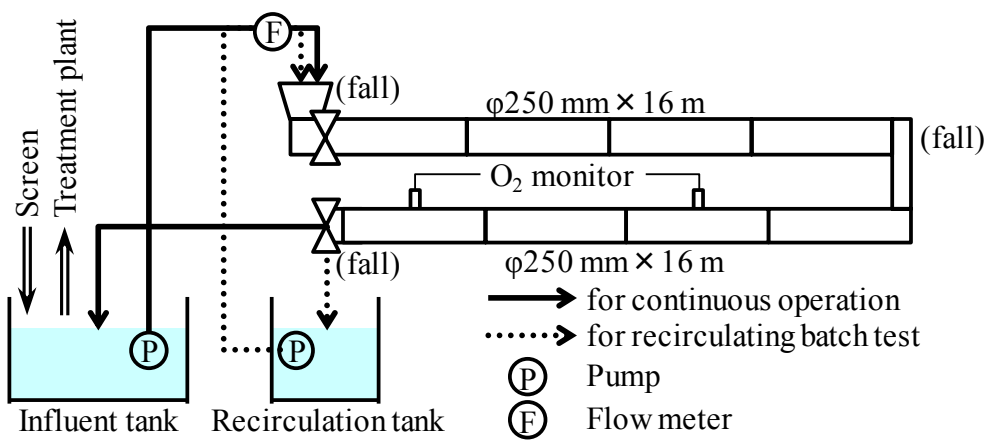

(b) Pilot-scale purifying pipe system

Fig. 1 - Schematic diagrams of the purifying pipe system for in-sewer treatment.

\section{MATERIALS AND METHODS}

\section{Setup and continuous operation of the purifying pipe system}

A pilot-scale purifying pipe system was set up in a WWTP receiving domestic wastewater from a small residential community (ca. 1000 PE) located in Nagareyama, Chiba, Japan. Although we could not strictly estimate the retention time of wastewater before reaching the WWTP, it seemed to take not more than $1 \mathrm{~h}$ considering the length of the collection pipes ( $<500 \mathrm{~m}$ from the WWTP), and thus the influent wastewater had scarcely been affected by self-purification yet.

The purifying pipe system consisted of eight polyvinyl chloride (PVC) pipes ( $4 \mathrm{~m}$ each in length and $250 \mathrm{~mm}$ in diameter), an influent tank, and a recirculation tank $\left(1 \mathrm{~m}^{3}\right)$ as illustrated in Fig. 1b. In the present system, the purifying pipe was designed for relatively small flow rate $\left(<15 \mathrm{~m}^{3} / \mathrm{h}\right)$ as illustrated in Fig. 1a. When the flow reached almost the designed maximum value (i.e., $15 \mathrm{~m}^{3} / \mathrm{h}$ ), the polyethylene (PE) sponge media in the lower deck were fully submerged. When the flow was very low $(<1-2$ $\mathrm{m}^{3} / \mathrm{h}$ ), most part of the sponge media was exposed to air even if the wastewater was leaked from the upper deck by irregular flow. Each pipe was connected smoothly and the slope was $8 \mathrm{~mm} / \mathrm{m}$ except for the three falls (ca. $50 \mathrm{~cm}$ each) at both ends and the middle $(0,16$, and $32 \mathrm{~m}$ from the start) of the purifying pipe (Fig. 1b). A flow meter was installed immediately before the purifying pipe. Dissolved oxygen (DO) was measured in the recirculation tank and oxygen concentration of gaseous phase was monitored inside the purifying pipe at 22 and $30 \mathrm{~m}$ from the start if needed. A 
transparent cross-sectional cover was installed at both ends of the purifying pipe ( 0 and $32 \mathrm{~m}$ from the start) so as to directly observe the separator and the media within the reach of a flashlight.

The influent was supplied to the top of the purifying pipe by pumping without any pre-treatment except for coarse screenings at $50 \mathrm{~mm}$ followed by $20 \mathrm{~mm}$. The influent pump was operated intermittently ( $30 \mathrm{~min}$ on/off) at $6-15 \mathrm{~m}^{3} / \mathrm{h}$ depending on recirculating batch tests, as stated below. The continuous operation was carried out for 9 months (from June 2014 to March 2015).

\section{Estimation of potential oxygen supply rate with water flow}

We examined the potential oxygen supply rate (i.e., maximum supply rate when DO is nearly zero) with water flow immediately after the system was set up (i.e., without biomass). In order to distinguish the effects of the separator and other factors, we also examined the potential oxygen supply rate without the separator. The recirculation tank was filled with $1 \mathrm{~m}^{3}$ of the supernatant of the final settler of the WWTP. The remaining DO was reduced to almost zero by adding sodium sulfite $(100 \mathrm{mg} / \mathrm{L})$ and cobalt chloride hexahydrate $(2 \mathrm{mg} / \mathrm{L})$. Then, the recirculation pump was turned on and DO concentration was monitored in the recirculation tank until it reached almost saturation at different flow rates $\left(5,10\right.$, and $\left.15 \mathrm{~m}^{3} / \mathrm{h}\right)$. First, the values of oxygen transfer coefficient $\left(k_{L} a\right)$ were calculated based on the following equation,

$k_{L} a=\ln \left(C_{\mathrm{O}_{2} \text {,sat }}-C_{\mathrm{O}_{2}}\right) / t_{\text {obs }}$

where $C_{\mathrm{O}_{2} \text {,sat }}$ is the saturation concentration of oxygen at experimental temperature, $C_{\mathrm{O}_{2}}$ is the monitored concentration of oxygen, and $t_{\mathrm{obs}}$ is the monitoring time after sulfite has been depleted. As for the temperature correction, we used the following equation to estimate $k_{L} a$ at $20^{\circ} \mathrm{C}$,

$k_{L} a_{20^{\circ} \mathrm{C}}=1.028^{(20-T)} \cdot k_{L} a$

where $T$ is the experimental temperature. Then, the calculated $k_{L} a$ at $20^{\circ} \mathrm{C}$ was converted into the potential oxygen supply rate per pipe length $\left(\mathrm{g}-\mathrm{O}_{2} /(\mathrm{m} \cdot \mathrm{d})\right)$ by using the total length of the pipe $(32 \mathrm{~m})$, the volume of the water $\left(1 \mathrm{~m}^{3}\right)$, and the flow rates.

\section{Estimation of oxygen supply rate without water flow}

We expected that the sponge media consumed a significant amount of oxygen when the flow is low (or the influent or recirculation pumps are off for this pilot system). Since the volume of remaining wastewater is much smaller than that of air without the water flow, it is reasonable to assume that the consumed oxygen corresponds to the supplied oxygen from the gaseous phase. Therefore, we examined the oxygen supply rate without water flow when the pilot system was stably operated and temperature was mild (October 2014, i.e., 4 months from the start). We sealed up both ends of the pipe after a 30 min supply of the wastewater and monitored the oxygen concentrations in the gaseous phase inside the pipe. Then, the oxygen supply rate $\left(\mathrm{g}-\mathrm{O}_{2} /(\mathrm{m} \cdot \mathrm{d})\right)$ was evaluated from the decrease in oxygen concentration and the total internal volume of the pipes. 


\section{Recirculating batch test}

The performance of the purifying pipe system was examined via a series of batch tests recirculating the wastewater for a day after the initial acclimation period for 3 weeks. The recirculation tank was filled with $1 \mathrm{~m}^{3}$ of the influent wastewater collected at 8 a.m., when the wastewater usually contained the highest COD in a single day. The recirculation pump was operated intermittently in the same way as in the continuous operation ( $30 \mathrm{~min}$ on/off) at $3,6,9,12$, or $15 \mathrm{~m}^{3} / \mathrm{h}$. The average temperature for the initial $4.5 \mathrm{~h}$ (used for calculation of COD removal rates) ranged from 18 to $29^{\circ} \mathrm{C}$. The batch tests were conducted in triplicate under each flow rate after the continuous operation at the same flow rate for more than a week (except for the $3 \mathrm{~m}^{3} / \mathrm{h}$ test, acclimated at $6 \mathrm{~m}^{3} / \mathrm{h}$ considering the stability of the pump). The wastewater samples were collected from the recirculating tank and analyzed at $0 \mathrm{~h}$, every hour from $0.5 \mathrm{~h}$ to $7.5 \mathrm{~h}$, and at $24.5 \mathrm{~h}$.

\section{Post-treatment experiment}

We investigated three types of post-treatments (gravity settling, membrane filtration, and coagulation) for samples taken at $0,0.5,1.5,3.5$, and $5.5 \mathrm{~h}$ of a recirculating batch test. All the post-treatments were carried out at the WWTP immediately after each sample was collected and screened $(0.85 \mathrm{~mm})$. As for the gravity settling, $500 \mathrm{~mL}$ of the sample was settled in a cylindrical plastic bottle for $30 \mathrm{~min}$, and about $100 \mathrm{~mL}$ of the supernatant was collected as the treated water. As for the membrane filtration, a 0.45- $\mu \mathrm{m}$ microfiltration (MF) membrane (Advantec A045A047A, Toyo Roshi, Japan) coupled with a prefilter (Whatman GF/A, GE Healthcare, UK) was used. This filtration method exactly resembled those used to obtain the samples for dissolved component analyses. As for the coagulation, $500 \mathrm{~mL}$ of the sample was put in a beaker equipped with a magnetic stirrer. Polyaluminum chloride (PAC) was added at a concentration of $50,100,200$, or $300 \mathrm{mg} / \mathrm{L}$ and mixed at $300 \mathrm{rpm}$ for $3 \mathrm{~min}$. Then $2 \mathrm{mg} / \mathrm{L}$ of polyacrylamide coagulant SKF-A553 (Sekisui Aqua Systems, Japan) was added and mixed at $150 \mathrm{rpm}$ for $2 \mathrm{~min}$. The formed flocks were settled for $10 \mathrm{~min}$ and the supernatant was collected as the treated water.

\section{Analytical methods}

After removing gross solids by a screen $(0.85 \mathrm{~mm})$, biochemical oxygen demand (BOD) and suspended solids (SS) were analyzed according to Japanese Industrial Standard JIS K 0102 (Japanese Standards Association, 2013). COD was measured by means of a commercially available kit (Hach, CO, USA). Anions and cations were analyzed by an ion chromatograph Dionex ISC-3000 (Thermo Fisher Scientific, MA, USA) equipped with a Dionex AS-12A column (Thermo Fisher Scientific) for anions or a TSKgel SuperIC-CR column (Tosoh, Japan) for cations. As stated previously, the MF membrane coupled with the prefilter was used to prepare samples for dissolved component analyses.

\section{RESULTS AND DISCUSSIONS \\ Oxygen supply with water flow}

The potential oxygen supply rates and $k_{L} a$ at $20^{\circ} \mathrm{C}$ with the recirculating water flow are summarized in Fig. 2. The observed $k_{L} a$ values of the purifying pipe including the separator were similar to those reported by Huisman et al. (2004b), ranging from 92 to 
256 in a full-scale pipe with almost the same diameter $(250-315 \mathrm{~mm})$ but twice the slope $(15 \mathrm{~mm} / \mathrm{m})$. Without the separator, on the other hand, the observed $k_{L} a$ values were merely one-third of those with the separator. These results imply that the separator plays more important role for the oxygen supply compared to other factors such as the flow and three falls. Moreover, the calculated $k_{L} a$ and potential oxygen supply rates clearly showed a linear increase with the flow rate from 5 to $15 \mathrm{~m}^{3} / \mathrm{h}$. Thus, we can estimate the potential oxygen supply rates based on the flow rates we adopted $(6-15$ $\mathrm{m}^{3} / \mathrm{h}$ for the continuous operation and $3-15 \mathrm{~m}^{3} / \mathrm{h}$ for the batch tests) and the aforesaid temperature correction for any experimental conditions.

\section{Oxygen supply without water flow}

We measured oxygen supply rate when water flow is stopped twice 4 months after starting the operation. When we stopped the wastewater supply (for $30 \mathrm{~min}$ ) and sealed up both ends of the pipe, a gradual decrease in oxygen concentration of the gaseous phase was observed (Fig. 3). The average decrease rate for the initial $1 \mathrm{~h}$ was ca. $6 \% / \mathrm{h}$ and corresponded to $20 \mathrm{~g} /(\mathrm{m} \cdot \mathrm{d})$ of oxygen supply to the attached biomass. These rates were equivalent to that by the water flow at $4 \mathrm{~m}^{3} / \mathrm{h}$ (Fig. 2), and thus, it is confirmed that both reaeration with water flow and direct exposure are the main sources of oxygen, especially when the flow is low.

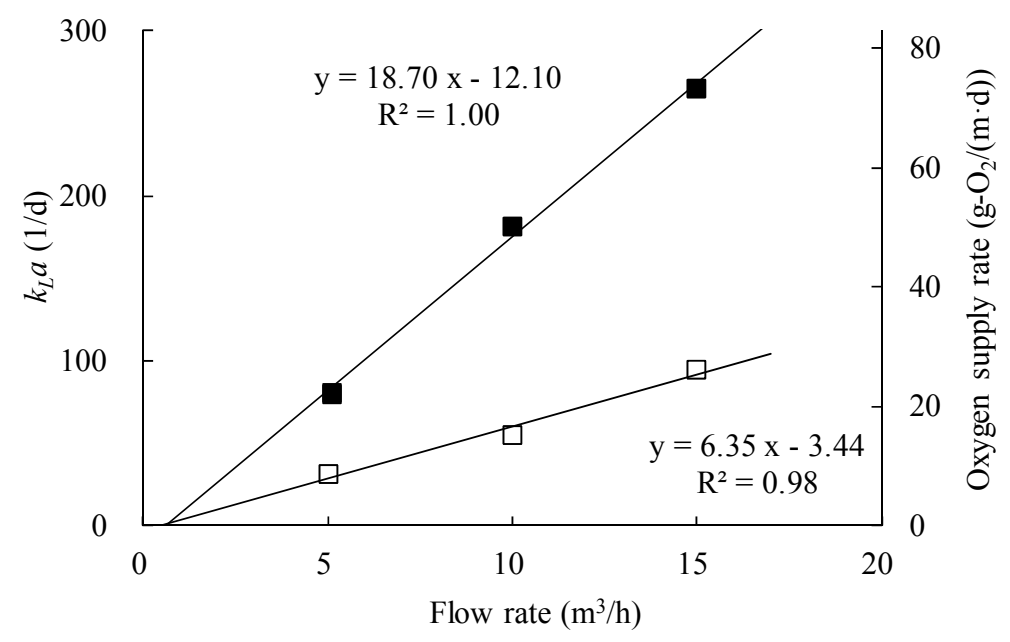

Fig. 2 - Potential oxygen supply rate and $k_{L} a$ at different flow rates with separator

(घ) or without separator $(\square)$. 


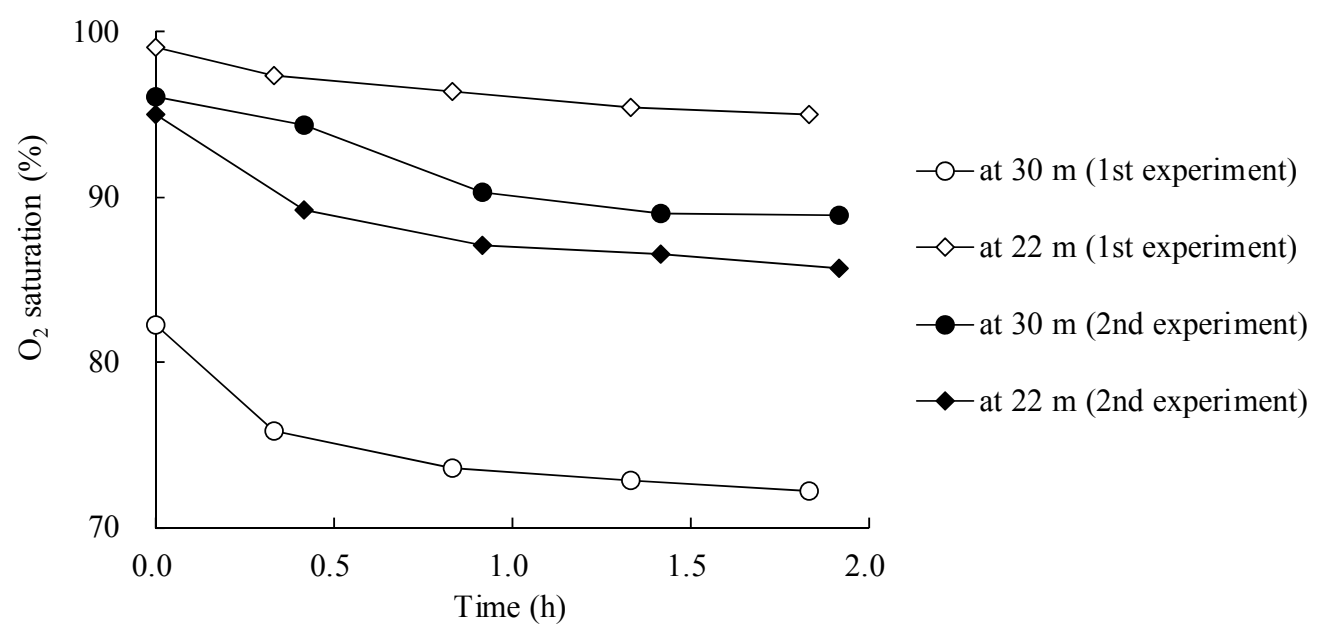

Fig. 3 - Oxygen saturation in the gaseous phase without water flow.

\section{Visual observation of the separator}

Although we could not quantitatively evaluate the attached or accumulated biomass and solids around the separator and media, we could monitor a part of them (several meters from both ends) through the transparent covers. For the first week of the operation, the sponge media rapidly got darker probably because of both the accumulation of suspended solids and the growth of biomass. After that, no significant shift in appearance was observed throughout the experimental period. As far as we observed from outside, therefore, the accumulation came into balance with the detachment in the early stage. Regarding the upper deck of the purifying pipe, there was a little biofilm on the separator; however, no blockage of the flow and no clogging of the holes were observed even after the 9 months operation. Nevertheless, further confirmation will be needed to evaluate the durability of the purifying pipe for longer term under various flow conditions.

\section{Performance of the purifying pipe system}

After the acclimation period for 3 weeks, the performance of the purifying pipe system was monitored 15 times at different flow rates by the one-day recirculating batch tests. An example of shifts in main water quality indices is shown in Fig. 4. The targets of the purifying pipe, i.e., organic matter such as COD (total and dissolved), BOD (total and dissolved), and SS linearly decreased in parallel for several hours and then plateaued. The shift in DO, a rapid increase followed by a plateau, also implies that biological degradation was active during the initial several hours. Although the decrease in organic matter was significant, the remaining concentrations were higher than those in the effluents of WWTPs even after one day of treatment (e.g., total COD $=152 \mathrm{mg} / \mathrm{L}$ ), presumably due to a lack of settling equipment. A similar trend was observed for $\mathrm{PO}_{4}{ }^{3-}-\mathrm{P}$ : it decreased by approximately $0.5 \mathrm{mg} / \mathrm{L}$ during the initial $5.5 \mathrm{~h}$. However, the purifying pipe was not effective for nitrogen removal, especially for nitrification. As shown in Fig. $4, \mathrm{NH}_{4}{ }^{+}-\mathrm{N}$ did not decrease even after the concentrations of organic matter and DO had plateaued. The sum of $\mathrm{NO}_{2}^{-}-\mathrm{N}$ and $\mathrm{NO}_{3}{ }^{-}-\mathrm{N}$ rapidly decreased; however, their initial concentrations were too small to evaluate the denitrification activity. Since insufficient nitrogen removal due to poor nitrification was observed in every one of our tests and 
agreed with previous studies for an actual sewer pipe (Pai et al., 2010) and in-lab experiments (Pai et al., 2013), we can concentrate on the removal of organic matter to estimate the oxygen balance. Nevertheless, it should also be noted that two research groups achieved significant nitrogen removal via nitrification by means of recirculating open-channel reactors in Thailand (Manandhar and Schroder, 1995; Karnchanawong and Polprasert, 1990). Thus, nitrogen removal deserves attention when the purifying pipe is operated under similar experimental conditions, such as a longer retention time and higher temperature.
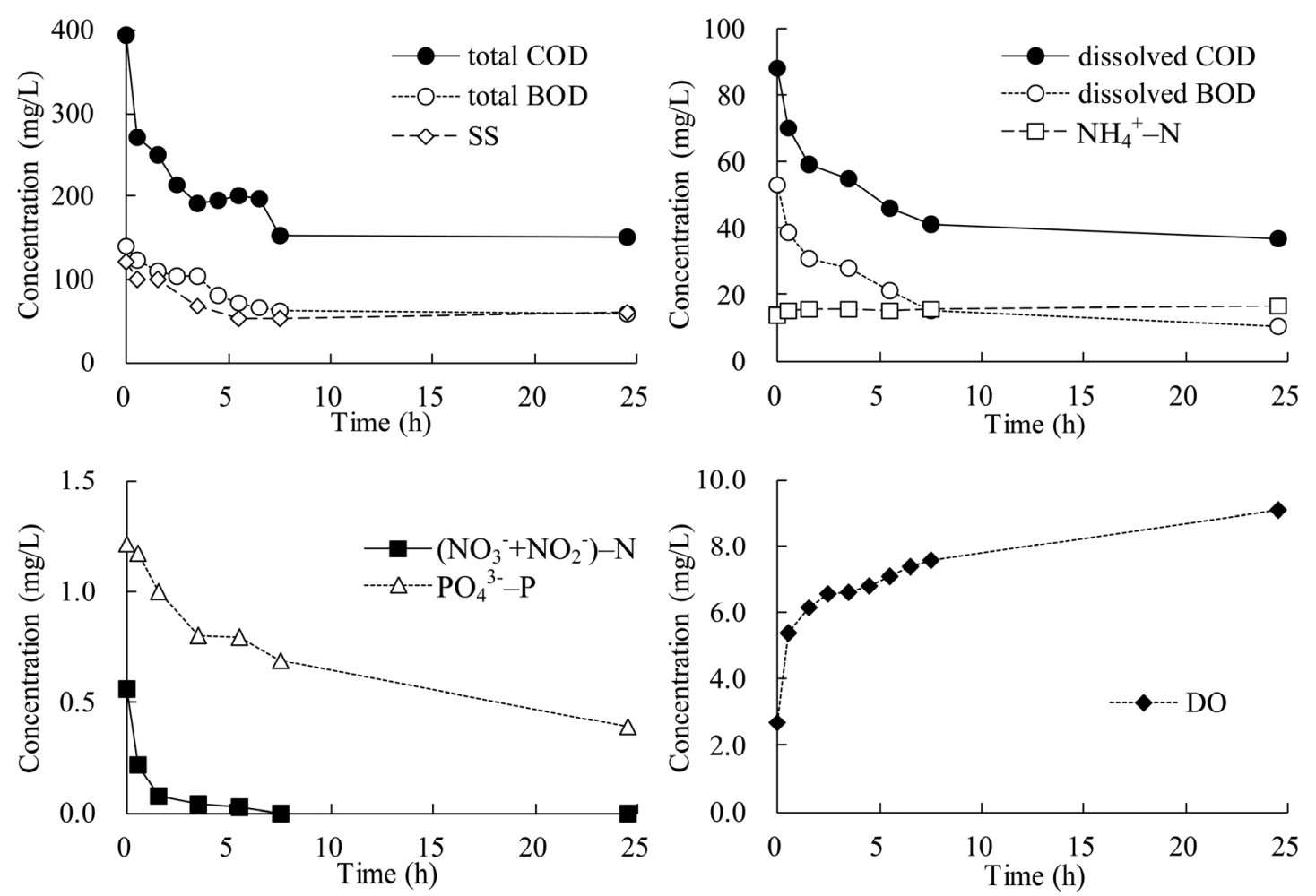

Fig. 4 - Shifts in water quality indices in a batch test.

(Recirculating flow $=12 \mathrm{~m}^{3} / \mathrm{h}$, influent $\mathrm{COD}=395 \mathrm{mg} / \mathrm{L}$, temperature $=21.2^{\circ} \mathrm{C}$.) 


\section{Effect of operational conditions}

Figure 5 shows the COD removal rates calculated from the slope for the initial $4.5 \mathrm{~h}$ under different operational conditions. The removal rates can be divided into three groups: one lower value $(6.7 \mathrm{~g}-\mathrm{COD} /(\mathrm{m} \cdot \mathrm{d}))$, twelve intermediate values $(12-28$ $\mathrm{g}-\mathrm{COD} /(\mathrm{m} \cdot \mathrm{d}))$, and two higher values $(35$ and $39 \mathrm{~g}-\mathrm{COD} /(\mathrm{m} \cdot \mathrm{d}))$. As for the lower value, it was presumably attributed to the lowest concentration of the influent COD (Fig. 5b) due to heavy rain, and thus, it was an exception. The higher values were other minor results, which might partly be attributed to both the higher flow rates (Fig. 5a) and the higher concentration of COD (Fig. 5b). As for the intermediate values (i.e., the majority), however, no clear trend was observed except for the gradual increase with the influent COD (Fig. 5b).

In general, flow rate (shear velocity) and concentration of target material are supposed to critically affect the activity of biofilm reaction because mass transfer through the surface of the biofilm is one of the main rate-limiting factors (e.g., Chen et al., 2001). In the purifying pipe, however, mass transfer had little effect, possibly because the sponge media could keep much more biomass than biofilm. Considering that flow rate and COD concentration are uncontrollable parameters for sewer pipes in use, it is of practical importance that the purifying pipe showed relatively constant performances (not less than $12 \mathrm{~g}-\mathrm{COD} /(\mathrm{m} \cdot \mathrm{d})$ ) for actual wastewater at wide ranges of flow rate $(3-$ $\left.15 \mathrm{~m}^{3} / \mathrm{h}\right)$ and COD concentrations $(275-432 \mathrm{mg} / \mathrm{L})$.

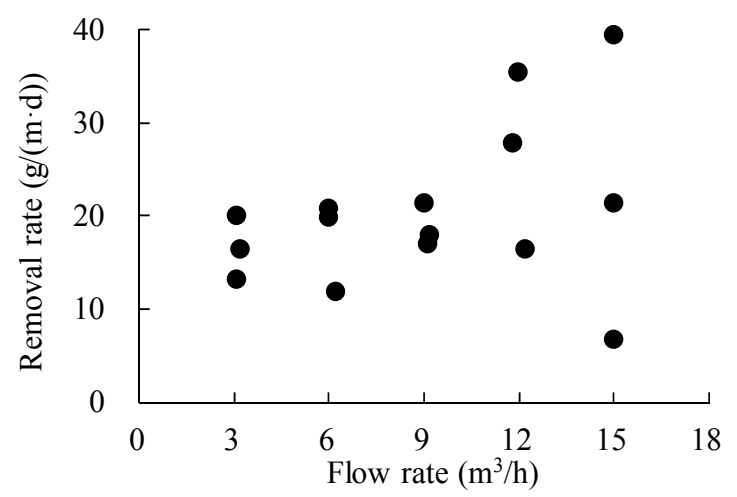

(a) Recirculating flow rate

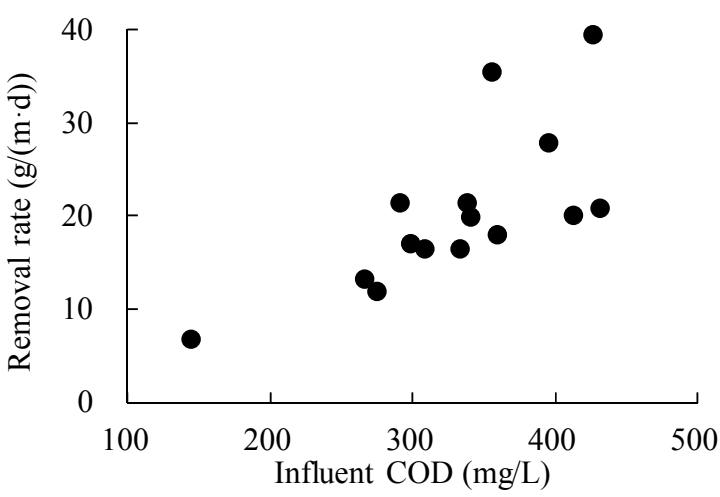

(b) Influent COD

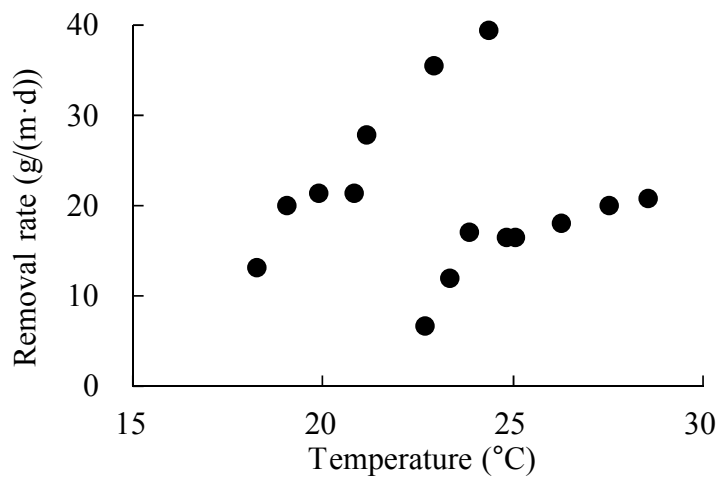

(c) Temperature

Fig. 5 - Effects of operational conditions on cod removal rates. 
On the other hand, temperature is expected to have more complicated effects: high temperature can enhance biological activity, while low temperature can result in efficient reaeration. As a result of the demonstration (Fig. 5c), it was found that temperature did not have a significant effect on the performance, at least for the tested conditions $\left(18-29^{\circ} \mathrm{C}\right)$. This result implies that higher temperature is not a potential problem for the purifying pipe system in most regions because wastewater temperature ranged no more than $29-33^{\circ} \mathrm{C}$ in pilot-scale recirculating reactors installed outdoors under shading, even in Thailand (Manandhar and Schroder, 1995; Karnchanawong and Polprasert, 1990). Nevertheless, the effect of lower temperature may call for further investigation considering that wastewater temperature could be lower than $10^{\circ} \mathrm{C}$ in winter in high-latitude and/or high-altitude regions such as Switzerland (Dürrenmatt and Wanner, 2014) or Denmark (Raunkjær et al., 1995).

\section{Oxygen balance}

Now that we have estimated the potential oxygen supply rate and the COD removal (oxidation) rate, we can roughly calculate the oxygen balance in the purifying pipe. Assuming that the biomass yield is $0.625 \mathrm{~g}$-COD/g-COD according to the Activated Sludge Models (Henze et al., 2000), the COD removal rate $(12-39 \mathrm{~g}-\mathrm{COD} /(\mathrm{m} \cdot \mathrm{d})$, except for the lowest value) can be converted into $5-15 \mathrm{~g}-\mathrm{O}_{2} /(\mathrm{m} \cdot \mathrm{d})$ of the oxygen consumption rate. On the other hand, the oxygen supply is mainly attributed to two factors stated above: reaeration with water flow and direct exposure without water flow. When the recirculation was operating, the potential oxygen supply rate ranged from 15 $\mathrm{g}-\mathrm{O}_{2} /(\mathrm{m} \cdot \mathrm{d})\left(\right.$ at $\left.3 \mathrm{~m}^{3} / \mathrm{h}\right)$ to $75 \mathrm{~g}-\mathrm{O}_{2} /(\mathrm{m} \cdot \mathrm{d})\left(\right.$ at $\left.15 \mathrm{~m}^{3} / \mathrm{h}\right)$ at $25^{\circ} \mathrm{C}$. Since the recirculation was shut down for half of the experimental period (30 min on/off), the potential oxygen supply rate by reaeration is estimated to be $8-38 \mathrm{~g}-\mathrm{O}_{2} /(\mathrm{m} \cdot \mathrm{d})$ for the $30 \mathrm{~min}$ on/off mode. Moreover, the actual oxygen supply rate might be from one-third to a half of the potential value because the observed DO saturation was not zero but $30-70 \%$ (Fig. 4) during the initial several hours. These estimation imply that reaeration may not be enough to compensate for the oxygen consumption $\left(5-15 \mathrm{~g}-\mathrm{O}_{2} /(\mathrm{m} \cdot \mathrm{d})\right)$, especially when the flow rate is relatively low. When the recirculation was shut off, however, the direct exposure could be an additional oxygen source at a rate of $20 \mathrm{~g}-\mathrm{O}_{2} /(\mathrm{m} \cdot \mathrm{d})$. Assuming that the exposure is effective only for half of the experimental period (i.e., when the recirculation stopped), the actual oxygen supply rate by direct exposure is estimated to be $10 \mathrm{~g}-\mathrm{O}_{2} /(\mathrm{m} \cdot \mathrm{d})$ for the $30 \mathrm{~min}$ on/off mode. The sum of the oxygen supply rates is 18 $-48 \mathrm{~g}-\mathrm{O}_{2} /(\mathrm{m} \cdot \mathrm{d})$ (assuming that the DO saturation is nearly zero) or $14-29 \mathrm{~g}-\mathrm{O}_{2} /(\mathrm{m} \cdot \mathrm{d})$ (assuming that the DO saturation is $50 \%$ ), and it is large enough compared to the consumption rate. In other words, it can be concluded that the performance of COD removal and the expected mechanisms for oxygen supply are consistent in terms of oxygen balance.

\section{Performance of the purifying pipe coupled with post-treatments}

Although the purifying pipe system can reduce loadings of organic matter to WWTPs at the end of the sewer network, the "effluent" contained COD and BOD at much higher levels than discharge regulations in most countries. If the biodegradable organic matter can almost be oxidized in the purifying pipe, however, simple post-treatments deserve careful attention as an alternative to construction/extension of conventional secondary treatment facilities consisting of aeration tanks and a final settler. Thus, we performed and compared three types of physicochemical post-treatments (gravity settling, 
membrane filtration, and coagulation) for samples taken at $0,0.5,1.5,3.5$, and $5.5 \mathrm{~h}$ of the batch test shown in Fig. 4. Since BOD is adopted as an official regulation in general, we evaluated the performances on a BOD basis in this section.

Figure 6a shows that coagulation by PAC is the most efficient post-treatment when the dosage is high enough $(100 \mathrm{mg} / \mathrm{L})$. The $140 \mathrm{mg} / \mathrm{L}$ of BOD in the influent was decreased to $104 \mathrm{mg} / \mathrm{L}$ by the purifying pipe treatment for $3.5 \mathrm{~h}$ and then successfully decreased to below $20 \mathrm{mg} / \mathrm{L}$ by the coagulation. It should also be noted that too much PAC was not effective: the residual BOD concentrations were $41 \mathrm{mg} / \mathrm{L}(\mathrm{PAC}=100 \mathrm{mg} / \mathrm{L}), 37 \mathrm{mg} / \mathrm{L}$ $(\mathrm{PAC}=200 \mathrm{mg} / \mathrm{L})$, and $37 \mathrm{mg} / \mathrm{L}(\mathrm{PAC}=300 \mathrm{mg} / \mathrm{L})$ for the influent. Although the filtration by a $0.45-\mu \mathrm{m}$ MF could also remove more than $60 \%$ of the residual BOD, the removal efficiencies were always smaller than those of the coagulation by $100 \mathrm{mg} / \mathrm{L}$ of PAC (Fig. 6b). This difference implies that the effluent of the purifying pipe still contained dissolved $(<0.45 \mu \mathrm{m})$ but high-molecular weight BOD such as colloidal components that could be removed by coagulation. On the other hand, gravity settling for 30 min showed that the removal ratio was only $20-40 \%$ and did not increase with the purifying pipe treatment. Although there is room for further investigation of the feature of each post-treatment, these results imply that the combination of the purifying pipe (replacing a conventional sewer pipe) and the optimized physicochemical treatment (replacing conventional secondary treatment) has the potential to be a novel option for developing or restructuring wastewater management systems.

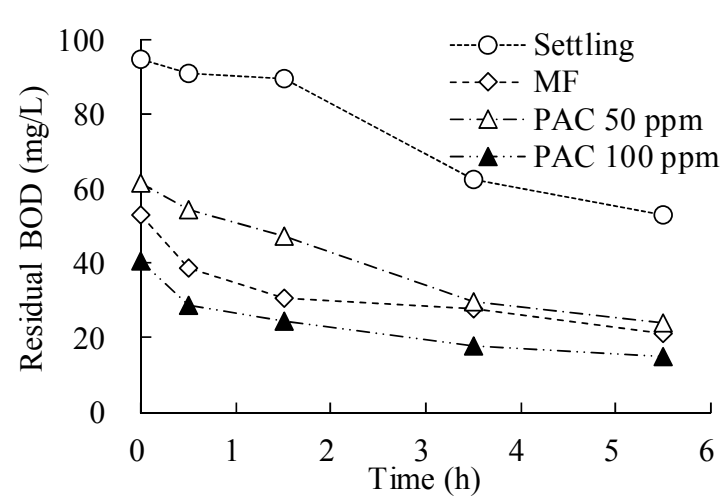

(a) Residual BOD concentration

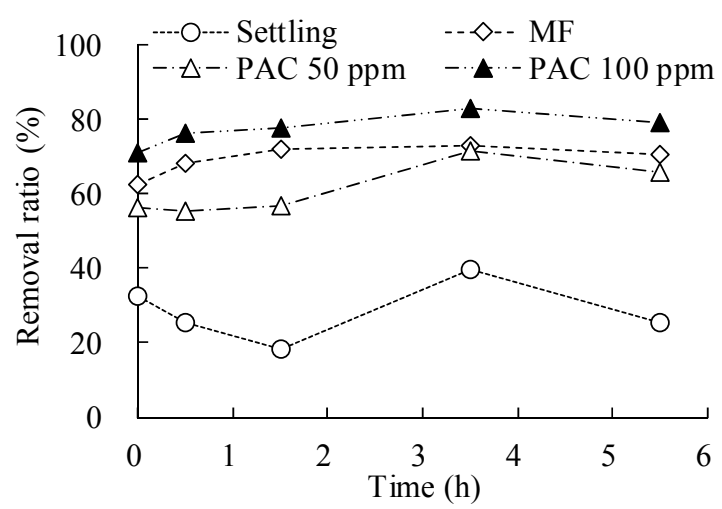

(b) BOD removal ratio to the effluent of the purifying pipe system

Fig. 6 - BOD removal by the purifying pipe system coupled with physicochemical post-treatments. 


\section{CONCLUSION}

The basic properties of a novel sewer pipe (purifying pipe) were investigated via a series of recirculating batch tests, and then the potential of the system coupled with physicochemical post-treatments was examined. From the results of these experiments, the following conclusions were obtained:

1) The purifying pipe was effective for organic matter removal. The main indices (COD, BOD, and SS) decreased significantly by intermittent recirculation for several hours.

2) The COD removal rates (per pipe length) ranged from 12 to $39 \mathrm{~g}-\mathrm{COD} /(\mathrm{m} \cdot \mathrm{d})$ and were not significantly affected by the recirculating flow rate $\left(3-15 \mathrm{~m}^{3} / \mathrm{h}\right)$ and temperature $\left(18-29^{\circ} \mathrm{C}\right)$.

3) The oxygen balance showed that the oxygen requirement for COD removal $(5-15$ $\left.\mathrm{g}-\mathrm{O}_{2} /(\mathrm{m} \cdot \mathrm{d})\right)$ was compensated by both potential reaeration with water flow $(8-38$ $\left.\mathrm{g}-\mathrm{O}_{2} /(\mathrm{m} \cdot \mathrm{d})\right)$ and direct exposure to air without water flow $\left(\mathrm{ca} .10 \mathrm{~g}-\mathrm{O}_{2} /(\mathrm{m} \cdot \mathrm{d})\right)$.

4) Coagulation using $P A C$ was an efficient post-treatment equivalent to conventional secondary treatment: $140 \mathrm{mg} / \mathrm{L}$ of the influent BOD was successfully decreased to below $20 \mathrm{mg} / \mathrm{L}$ by the purifying pipe (recirculation for $3.5 \mathrm{~h}$ ) followed by coagulation $(100 \mathrm{mg} / \mathrm{L}$ of PAC).

\section{ACKNOWLEDGMENTS}

The authors are grateful to the Komagidai Daini neighborhood community association and Daishin Clear Inc., the owner and the subcontract manager of the WWTP, for their understanding and cooperation in conducting the experiments.

\section{REFERENCES}

Almeida M. D. C., Butler D. and Davies J. W. (1999) Modeling in-sewer change in wastewater quality under aerobic conditions. Water Sci. Technol., 39(9), 63-71.

Baban A. and Talinli I. (2009) Modeling of organic matter removal and nitrification in sewer systems - an approach to wastewater treatment. Desalin., 246, 640-647.

Chen G. H., Leung D. H. W. and Huang J. C. (2001) Removal of dissolved organic carbon in sanitary gravity sewer. J. Environ. Eng., 127, 295-301.

Dürrenmatt D. J. and Wanner O. (2014) A mathematical model to predict the effect of heat recovery on the wastewater temperature in sewers. Water Res., 48, 548-558.

Gall B., Takács I. and Patry G. (1995) The effect of organic reactions in a collection system on wastewater treatment plant performance. Water Sci. Technol., 31(7), 25-31.

Green M., Shelef G. and Messing A. (1985) Using the sewerage system main conduits for biological treatment - greater Tel-Aviv as a conceptual model. Water Res., 19, 1023-1028.

Henze M., Gujer W., Mino T. and van Loosdrecht M. C. M. (2000) Activated Sludge Models ASM1, ASM2, ASM2d and ASM3. Scientific and Technical Repost No.9, IWA Publishing, London, UK.

Huisman J. L., Gasser T., Gienal C., Kühni M., Krebs P. and Gujer W. (2004a) Quantification of oxygen fluxes in a long gravity sewer. Water Res., 38, 1237-1247.

Huisman J. L., Weber N. and Gujer W. (2004b) Reaeration in sewers. Water Res., 38, 1089-1110. 
Japanese Standards Association (2013) Testing Methods for Industrial Wastewater, JIS K 0102:2013. Japanese Standards Association, Tokyo, Japan. (in Japanese)

Karnchanawong S. and Polprasert C. (1990) Organic carbon and nitrogen removal in attached-growth circulating reactor (AGCR). Water Sci. Technol., 22(3/4), 179-186.

Koch C. M. and Zandi J. (1973) Use of pipelines as aerobic biological reactors. J. Water Pollut. Control Fed., 45, 2537-2548.

Manandhar U. K. and Schroder H. (1995) Sewage circulating reactor - an approach to recirculating wastewater in sewers. Environ. Technol., 16, 201-212.

Marjaka I. W., Miyanaga K., Hori K., Tanji Y. and Unno H. (2003) Augmentation of self-purification capacity of sewer pipe by immobilizing microbes on the pipe surface. Biochem. Eng. J., 15, 69-75.

Nielsen P. H., Raunkjær K., Norsker N. H., Jensen N. A. and Hvitved-Jacobsen T. (1992) Transformation of wastewater in sewer systems - a review. Water Sci. Technol., 25(6), 17-31.

Pai T. Y., Chen C. L., Chung H., Ho H. H. and Shiu T. W. (2010) Monitoring and assessing variation of sewage quality and microbial functional groups in a trunk sewer line. Environ. Monit. Assess., 171, 551-560.

Pai T. Y., Shyu G. S., Chen L., Lo H. M., Chang D. H., Lai W. J., Yang P. Y., Chen C. Y., Liao Y. C. and Tseng S. C. (2013) Modelling transportation and transformation of nitrogen compounds at different influent concentrations in sewer pipe. Appl. Math. Modell., 37, 1553-1563.

Pomeroy R. D. and Parkhurst J. D. (1972) Self-purification in sewers. Proc. $6^{\text {th }}$ Int. Conf. on Water Pollut. Res., Jerusalem, Israel, June 18-23, 1-16.

Raunkjær K., Hvitved-Jacobsen T. and Nielsen P. H. (1995) Transformation of organic matter in a gravity sewer. Water Environ. Res., 67, 181-188.

Tanji Y., Sakai R., Miyanaga K. and Unno H. (2006) Estimation of the self-purification capacity of biofilm formed in domestic sewer pipes. Biochem. Eng. J., 31, 96-101. 